\title{
Frequency and characteristics of advanced cancer patients with COVID + ve status among inpatient supportive care consults during the pandemic: experience from a tertiary cancer center
}

\author{
Sriram Yennurajalingam ${ }^{1} \cdot$ Zhanni Lu $^{1} \cdot$ Minxing Chen $^{2} \cdot$ Eduardo Bruera $^{1}$ \\ Received: 31 March 2021 / Accepted: 29 August 2021 / Published online: 12 October 2021 \\ (c) The Author(s), under exclusive licence to Springer-Verlag GmbH Germany, part of Springer Nature 2021
}

\begin{abstract}
Purpose There is limited literature available regards the frequency and characteristics of COVID-19+ ve status among advanced cancer patients referred to an inpatient supportive care consultation(PC) at a tertiary cancer center. Our study aimed to determine the frequency and characteristics of COVID-19+ ve cancer patients seen by PC.

Methods Advanced cancer patients seen as a consult by PC between June 15 and September 25, 2020, at MD Anderson Cancer Center were eligible for the study. We evaluated the patient demographics, clinical characteristics including symptoms(ESAS), delirium(MDAS), COVID + status prior to, and after PC referral(converters), and type of PC delivery(in person or virtual care).

Results Sixty-six out of 1380 (4.8\%) PC consults were COVID-19 + ve: 42 prior to PC (79\%), and 14 (21\%) were COVID$19+$ ve after the PC (converters). COVID-19+ PC patients had lower depression $(P=.035)$, spiritual distress $(P=.003)$, and were more seen frequently virtually $(P<0.001)$. There was no significant difference between COVID-19-ve patients and converters. Converters had higher symptom distress $(P=0.007)$, lower delirium $(P=0.014)$, and were referred earlier $(P=.011)$ compared to COVID + PC patients diagnosed prior to PC consult. Overall, patients seen virtually compared inperson by $\mathrm{PC}$ were younger $(P=0.02)$ and had lower delirium $(P=0.007)$.

Conclusion The burden of COVID-19+ status among patients referred to PC was low. COVID-19+ ve patients had more frequent virtual visits, lower depression, and spiritual distress scores. Patient seen virtually were significantly younger and had lower delirium. During a new pandemic, universal virtual care might be emphasized especially at initial encounters after admission and further research is needed on the potential efficacy of this intervention.
\end{abstract}

Keywords Supportive cancer care · Palliative care · COVID-19 · Virtual care · Cancer symptoms

\section{Introduction}

Coronavirus SARS-COV2 (COVID-19) pandemic started in Wuhan, Hubei Province of the People's Republic of China, around December 2019, and has since overwhelmed health care across the world [1,2]. Globally, palliative care due to holistic approach has been an essential component

Sriram Yennurajalingam

syennu@mdanderson.org

1 Department of Palliative Care, Rehabilitation Medicine, and Integrative Medicine, UT MD Anderson Cancer Center, 1515 Holcombe Blvd. Unit 1414, Houston, TX 77030, USA

2 Biostatistics, UT MD Anderson Cancer Center, Houston, TX, USA of universal health care [3]. COVID-19 pandemic further emphasized the role of palliative care as an essential service in cancer patients. Optimal management of patients' distressing symptoms, clinical uncertainties, complex decision-making, and strengthening care provided to the family caregivers thereby improving patients' quality of life are the key attributes of palliative practice that are very much needed during this difficult period [4]. Based on prior research by our team at MD Anderson Cancer Center, the term "supportive care" in contrast to "palliative care" is used to describe the service as it was associated with improved perception among patients and health care providers resulting in improved palliative care referrals $[5,6]$. We therefore changed our palliative care service name at MD Anderson Center to "supportive care" since 2011 [5, 6]. The essential services provided within the purview of supportive care 
service included pain and symptom management, facilitating communication, counseling, spiritual care, goals of care discussion, and end of life care. The pandemic had devastating effects among palliative care health care providers both in the hospital (outpatient and inpatient) and home settings. The negative effects included fear of infection to their family and themselves, significant limitations and logistics barriers in terms of access to patients and caregivers, and personal hardships due to lack of social networking with family friends, workplace resulting in psychological distress, sleep disturbance, and worsening of chronic illness [7, 8]. There is limited published literature on the frequency COVID-19+ve status among hospitalized inpatient supportive care referrals seen at a tertiary cancer center during the pandemic, the characteristics of patients with and without COVID$19+$ ve status during the pandemic, and how they differed in terms of symptom distress when seen in person vs. virtually. There is also limited understanding of the patients who have converted to COVID-19 + ve after the inpatient supportive care consultation (PC). This information would also help to characterize the cancer patients receiving palliative care during COVID-19, and thereby develop effective strategies to provide effective care to all COVID-19+, and nonCOVID-19 + patients by PC teams. This information would also be helpful for provision safe care by the PC team due to lack of availability of all personal protective precautions in a universal basis for the PC teams. Therefore, our study aimed to determine the frequency, and characteristics of COVID + ve patients seen by inpatient supportive care service $(\mathrm{PC})$. We also examined the demographics and clinical characteristics of those patients who were COVID-19+ve prior to and after PC consults, and PC patients seen virtually and in-person (face-face) during the pandemic.

\section{Methods}

This study was approved by the institutional review board (IRB) of the University of Texas, MD Anderson Cancer Center, Houston, TX. The IRB waived the requirement for informed consent from all the patients reviewed in this retrospective study.

Patients were eligible for this study if the advanced cancer patient was seen as a consult by the inpatient mobile supportive care team (PC) between June 15 and September 25, 2020 , at the emergency room, clinical decision units, inpatient floors, or intensive care units, at University of Texas MD Anderson Cancer Center. Patients referred to inpatient PC were included in the study because only a part of the patients referred to inpatient $\mathrm{PC}$ were able to be seen virtually in contrast to outpatient PC due to patient-related factors such as severity of symptom distress, delirium which are more severe in inpatient settings, and logistic issues such as limited access to patient caregivers to facilitate the virtual services due to strict visitation policy (see Appendix A).

In this retrospective review study, we reviewed the electronic medical records of the eligible advanced cancer patients seen by PC team. Demographics and patients' clinical assessments that are routinely collected as a part of the patient's clinical care were reviewed. The characteristics included age, gender, race/ethnicity, cancer type, insurance status, the Eastern Cooperative Oncology Group (ECOG) performance status, the Edmonton Symptom Assessment Scale (ESAS), Memorial Delirium Assessment Scale (MDAS), and the Cut Down, Annoyed, Guilty, Eye openerAdapted to Include Drugs (CAGE-AID) questionnaire.

ECOG was used to measure patients' performance status. It is a validated 5 -point scale $(0=$ fully active, able to carry all pre-disease performance without restriction to $5=$ dead) [9].

ESAS is a validated instrument used to assess symptoms on a $0-10$ numerical scale $(0$, no symptoms; 10 , worst possible symptoms) in advanced cancer patients. Pain, fatigue, nausea, depression, anxiety, drowsiness, shortness of breath, appetite, feelings of well-being, sleep, financial distress, and spiritual pain were assessed using this instrument $[10,11]$. Symptom distress score is defined as a composite score of the symptoms on the 9 ESAS symptoms (pain, fatigue, nausea, depression, anxiety, drowsiness, shortness of breath, appetite, feelings of well-being) [11].

CAGE-AID is a 4-item questionnaire used to assess alcoholism and illicit drug use [12]. A score of 2 or more is considered positive for alcoholism. CAGE-AID questionnaire was routinely administered in all patients seen by PC because prior studies by our team and others have found that CAGE-AID + ve patients tend to have high levels of symptoms distress and have a higher risk for non-medical opioid use [13, 14].

MDAS is a validated clinician rated 10-item severity rating scale assess delirium in advanced cancer patients [15]. Each item is scored from 0 to 3 depending on its intensity and frequency (possible range, $0-30$ ). A score of 7 out of 30 was associated with the diagnosis of delirium [16].

\section{Inpatient supportive care consultation service}

Referrals to PC consults were primarily from inpatient medical, surgery, and gynecology oncology services, with fewer referrals coming via admissions from our emergency center and outpatient's clinics at MD Anderson. The reasons for consults included physical, psychosocial distress, family distress, goals of care discussion, or transition to end of life care. The patient is assessed routinely using a standardized checklist which includes the ESAS, CAGE questionnaire, and MDAS [17]. Patients with advanced cancer referred to inpatient $\mathrm{PC}$ have a high frequency of delirium, which is 
often missed by the primary oncology team, and this may be due to the lack of routine screening of delirium using a validated tools [18]. Therefore, MDAS is a routinely done as part of PC consultation and follow-up care. The care follows a standardized management plan as per M. D. Anderson supportive care standard of care guidelines [19]. A board-certified palliative care physician with a palliative care fellow or advance practice provider performs the consult. They request that the participation of the other appropriate members of the interdisciplinary team (psychologists, chaplaincy, pharmacists, and social worker) is based on the individual needs of the patients and their families. The virtual PC service practiced during the pandemic had similar composition as the routine in-person PC visits with all members if the interdisciplinary team contributing to the virtual care of patients and their family. Referrals to the 12-bed dedicated supportive care unit were primarily through transfers from other oncology inpatient services, with fewer referrals coming via admissions from our emergency center and at MD Anderson. The admission criteria for the supportive care unit included the presence of severe physical and psychosocial distress and/or family distress among patients with advanced or terminal disease. The criteria for inpatient palliative care unit admission were consistent with the criteria outlined in the guidelines on Supportive and Palliative care published by the European Society of Medical Oncology [20]. All patients met the acute care criteria required for hospitalization.

During the pandemic, our institution, as per the state, and the Center of disease and Prevention (CDC) guidelines have implemented various measures to control the spread including isolation of COVID-19+ patients in separate floors, strict precautions including daily screening of employees and patients, COVID-19 + testing of all patients, limiting visitation for patients family and friends, use of surgical facemasks, face shields, and hand hygiene. During the first wave of the pandemic (2020), there was a delay (8-24 h) between the COVID-19 test which was administered in asymptomatic COVID-19-negative patients admitted to the hospital, and the results (see Appendix A-COVID-19 testing policy our institution). The PC providers were usually consulted at the time of admission or prior to admission in certain instances from emergency room or ambulatory centers of the hospital. The PC encounter that occurs during this time lag when the COVID-19 test results is still not known increases the risk of the PC providers of getting infected, spreading infections to fellow health care providers and other patients seen by PC providers who are COVID-19 negative later that day or day after. This is because PC providers were not provided all the PPE precautions provided in floors dedicated to COVID-19-positive patients (N-95 masks, gloves, face shields for eye protections, protective gowns) due limited supply. Attached in the Appendix A is the MD Anderson Cancer Center testing policy. In brief, MD Anderson uses a time plus symptom strategy for clearing infected patients and employees. Based on the state and CDC guidelines, COVID test was considered valid for 3 days for both outpatients and inpatients. In both outpatients as well as inpatients patients, COVID testing was repeated after 3 days in patients who had a negative COVID test if symptomatic, or in asymptomatic patients prior to their admission, surgeries, or some procedures and treatments, including before radiation treatment, stem cell transplant, high-dose induction chemotherapy, and certain cellular therapy infusions. Additionally, PC service developed a "COVID-19 Tracking and Alert List" among the patient referred to $\mathrm{PC}$ with a goal to facilitate maintaining continuous care of COVID-19 patients by PC using virtual care as well as provide protection and care for the $\mathrm{PC}$ health care providers and all patients seen by PC safely during daily routine care. This also involved proactive testing, and quarantine of those $\mathrm{PC}$ providers who were infected. As an example, when the patients referred to $\mathrm{PC}$ were tested positive for COVID-19 after the PC consult (converters), the PC clinicians were advised to be tested for the COVID-19 for prevention of contagion, and personal care.

\section{Statistical analysis}

Patient demographics and clinical characteristics were summarized using descriptive statistics such as mean, standard deviation, frequency, and proportions. The frequency and proportion of COVID-19 + ve PC patients, converters and COVID-19-ve PC patients, patients seen virtually, and seen in person (face-face) were estimated.

For sample size calculation, the primary outcome of interest was the ESAS symptom distress score, the sum of ESAS pain, dyspnea, appetite, nausea, fatigue, drowsiness, anxiety, depression, and well-being item scores. A two group $t$ test with a 0.050 two-sided significance level of $80 \%$ power was able to detect a difference in means of 0.581 , assuming that the common standard deviation is 1.00 , when the sample sizes in the two groups (converters, and COVID-19-ve PC patients) are 30 and 110, respectively. This sample size calculation was performed using nQuery Advisor 7.0.

A random sample of COVID-19-ve, in person, and virtual PC patients were selected $(n=100)$ to compare COVID-19+ve vs. COVID-19-ve PC patients, and in-person vs. virtual PC patients. Two-sample $t$ test was used to compare the continuous characteristics, and chi-squared/ Fisher exact test was used to compare the categorical characteristics between groups. All computations were carried out in SAS 9.4 (SAS Institute Inc., Cary, NC, USA, or Stata 15 (StataCorp. 2017. Stata Statistical Software: Release 15. College Station, TX: StataCorp LLC)). 
Table 1 Patient demographics and characteristics of inpatient supportive care patients who were COVID + and COVID-ve

\begin{tabular}{|c|c|c|c|c|}
\hline Covariates & Total & COVID-ve & COVID + ve & \\
\hline Gender $(N, \%)$ & & & & p-value* \\
\hline Female & $91(55 \%)$ & $56(56 \%)$ & $35(53 \%)$ & 0.71 \\
\hline \multicolumn{5}{|l|}{ Race $(N, \%)$} \\
\hline White & $106(64 \%)$ & $71(71 \%)$ & $35(53 \%)$ & \multirow[t]{4}{*}{0.027} \\
\hline African American & $35(21 \%)$ & $15(15.0 \%)$ & $20(30 \%)$ & \\
\hline Asian & $6(3.6 \%)$ & $5(5.0 \%)$ & $1(1.5 \%)$ & \\
\hline Other & $19(11.4 \%)$ & $9(9.0 \%)$ & $10(15.2 \%)$ & \\
\hline \multicolumn{5}{|l|}{ Ethnicity $(N, \%)$} \\
\hline Hispanic or Latino & $40(24.1 \%)$ & $17(17.0 \%)$ & $23(34.8 \%)$ & \multirow[t]{3}{*}{0.018} \\
\hline Not Hispanic or Latino & $120(72.3 \%)$ & $80(80.0 \%)$ & $40(60.6 \%)$ & \\
\hline Unknown & $6(3.6 \%)$ & $3(3.0 \%)$ & $3(4.5 \%)$ & \\
\hline \multicolumn{5}{|l|}{ Cancer diagnosis $(N, \%)$} \\
\hline Breast & $12(7.2 \%)$ & $4(4.0 \%)$ & $8(12 \%)$ & \multirow[t]{8}{*}{$\mathbf{0 . 0 3 3}$} \\
\hline Gastrointestinal & $35(22 \%)$ & $24(24.0 \%)$ & $11(16.7 \%)$ & \\
\hline Genitourinary & $24(14.5 \%)$ & $15(15.0 \%)$ & $9(13.6 \%)$ & \\
\hline Gynecological & $21(12.7 \%)$ & $13(13.0 \%)$ & $8(1 \%)$ & \\
\hline Head and neck & $10(6.0 \%)$ & $5(5.0 \%)$ & $5(7.6 \%)$ & \\
\hline Hematologic & $38(23 \%)$ & $17(17.0 \%)$ & $21(32 \%)$ & \\
\hline Other & $9(5.4 \%)$ & $7(7.0 \%)$ & $2(3.0 \%)$ & \\
\hline Thoracic & $17(10.2 \%)$ & $15(15.0 \%)$ & $2(3.0 \%)$ & \\
\hline Cancer-directed treatment $(N, \%)^{\dagger}$ & $14(8.4 \%)$ & $9(9.0 \%)$ & $5(7.6 \%)$ & 0.75 \\
\hline \multicolumn{5}{|l|}{ Insurance $(N, \%)$} \\
\hline Government & $66(39 \%)$ & $39(39.0 \%)$ & $27(41)$ & \multirow[t]{3}{*}{0.87} \\
\hline Private insurance & $83(50.0 \%)$ & $52(52.0 \%)$ & $31(47.0 \%)$ & \\
\hline Self-pay & $17(11 \%)$ & $9(9.0 \%)$ & $8(12 \%)$ & \\
\hline \multicolumn{5}{|l|}{ Visit type $(N, \%)$} \\
\hline In person & $69(41.6 \%)$ & $54(54.0 \%)$ & $15(22.7 \%)$ & \multirow[t]{2}{*}{$<0.001$} \\
\hline Telemedicine & $97(58.4 \%)$ & $46(46.0 \%)$ & $51(77.3 \%)$ & \\
\hline \multicolumn{5}{|l|}{$\operatorname{CAGE}(N, \%)$} \\
\hline 0-1 & $142(93.4 \%)$ & $91(95.8 \%)$ & $51(85.5 \%)$ & \multirow[t]{2}{*}{0.28} \\
\hline $2-4$ & $10(6.6 \%)$ & $4(4.3 \%)$ & $6(10.6 \%)$ & \\
\hline \multicolumn{5}{|l|}{$\operatorname{ECOG}(N \%)$} \\
\hline 0-2 & $96(62 \%)$ & $57(57.6 \%)$ & $39(70 \%)$ & \multirow[t]{2}{*}{0.15} \\
\hline $3-4$ & $59(38 \%)$ & $42(42.4 \%)$ & $17(30 \%)$ & \\
\hline \multicolumn{4}{|l|}{ Variable, $N$, mean (SD) } & \multirow{2}{*}{$\begin{array}{l}\text { p-value } * * * \\
0.34\end{array}$} \\
\hline Age & $166,58(13.9)$ & $100,59(13.2)$ & $66,57(15)$ & \\
\hline \multicolumn{5}{|l|}{$\begin{array}{l}\text { Assessments } \\
\text { ESAS, } N \text {, mean (SD) }\end{array}$} \\
\hline Anxiety & $156,2.79(3.06)$ & $100,2.94(3.05)$ & $56,2.52(3.1)$ & 0.41 \\
\hline Anorexia & $149,4.8(3.27)$ & $99,4.9(3.33)$ & $50,4.6(3.18)$ & 0.61 \\
\hline Depression & $154,1.58(2.5)$ & $100,1.87(2.7)$ & $54,1.06(2)$ & $\mathbf{0 . 0 3 5}$ \\
\hline Drowsiness & $155,2.45(2.75)$ & $100,2.63(2.84)$ & $55,2.11(2.6)$ & 0.26 \\
\hline Fatigue & $155,5.70(2.7)$ & $100,6.01(2.43)$ & $55,5.13(3.06)$ & 0.07 \\
\hline Financial distress & $116,1.19(2.54)$ & $78,1.10(2.45)$ & $38,1.37(2.74)$ & 0.6 \\
\hline Nausea & $158,1.71(2.57)$ & $100,1.68(2.62)$ & $58,1.76(2.52)$ & 0.85 \\
\hline Pain & $159,5.45(3.20)$ & $100,5.47(3.1)$ & $59,5.42(3.37)$ & 0.93 \\
\hline Sleep disturbance & $145,3.97(3.27)$ & $96,4.01(3.3)$ & $49,3.90(3.22)$ & 0.84 \\
\hline Dyspnea & $154,2.04(2.84)$ & $99,1.77$ (2.59) & $55,2.53(3.2)$ & 0.14 \\
\hline Spiritual & $130,0.35(1.36)$ & $88,0.52(1.63)$ & $42,0.00(.00)$ & .003 \\
\hline Feeling of well-being & $119,4.30(2.6)$ & $83,4.49(2.5)$ & $36,3.86(2.8)$ & 0.22 \\
\hline
\end{tabular}


Table 1 (continued)

\begin{tabular}{lllll}
\hline Covariates & Total & COVID-ve & COVID + ve & \\
\hline Symptom distress score & $117,30.34(13)$ & $81,30.96(13.2)$ & $36,28.94$ & 0.44 \\
& & & $(12.3)$ & \\
MDAS & $152,2.01(4.03)$ & $97,2.35(4.76)$ & $55,1.42(2.1)$ & 0.099 \\
$\begin{array}{l}\text { Admission to inpatient supportive } \\
\text { care consultation, days, } \boldsymbol{N} \text {, mean } \\
\quad \text { (SD) }\end{array}$ & $166,3.07(5.63)$ & $100,2.49(4.87)$ & $66,3.95(6.57)$ & 0.10 \\
$\begin{array}{l}\text { Follow-ups, mean (SD) } \\
\text { Visit type }\end{array}$ & $6(10)$ & $6(7)$ & & \\
$\begin{array}{l}\text { Inpatient SCC consult mode, } \boldsymbol{N}(\%) \\
\text { In person }\end{array}$ & $695(50.4 \%)$ & $15(22.7 \%)$ & $680(51.8 \%)$ & $<.001$ \\
$\begin{array}{l}\text { Telemedicine } \\
\text { Visit type }\end{array}$ & $685(49.6 \%)$ & $51(77.3 \%)$ & $634(48.2 \%)$ & \\
$\begin{array}{l}\text { Inpatient SCC follow-up mode, } \boldsymbol{N}(\%) \\
\text { In person }\end{array}$ & $677(54.1 \%)$ & $19(32.8 \%)$ & $658(55.2 \%)$ & .001 \\
Telemedicine & $574(45.9 \%)$ & $39(67.2 \%)$ & $535(44.8 \%)$ & \\
\hline
\end{tabular}

Bolded $P$ values indicate a statistically significant difference

Abbreviations: SD, standard deviation; ECOG Performance Status, Eastern Cooperative Oncology Group performance status; CAGE-AID, Cut Down-Annoyed-Guilty-Eye Opener assessment; ESAS, Edmonton Symptom Assessment System; SDS, ESAS Symptom Distress Score; MDAS, Memorial Delirium Assessment Scale

${ }^{*} P$ value was estimated by $\mathrm{Chi}^{2} /$ Fisher's exact test

${ }^{* *} P$ value was estimated by $t$ test

${ }^{\dagger}$ Cancer-directed treatment-14 days prior to, or during the admission. It includes, surgery, procedures, radiation therapy, intravenous chemotherapy, targeted therapy, or immunotherapy

\section{Results}

Sixty-six out of 1380 (4.8\%) PC consults were COVID$19+$ ve, and 42 out of 66 were found to be COVID-19+ ve prior to PC consult (79\%), and 14 (21\%) were found to COVID-19+ ve after the PC consult (converters). All patients had follow-up visits after PC consultation, with median (interquartile range) frequency of follow-up visits of $4(2,8) .49 .6 \%(n=685)$, and $45.9 \%(n=574)$ patients received virtual services at consult and follow-up visits, respectively. Table 1 shows that mean and standard deviation for age was 58 and 13.9, female was 55\%; CAGE + ve $(\geq 2)$ were $6.6 \%$, and ECOG '2 was $38 \%$. Mean (SD) ESAS pain was 5.45 (3.20), ESAS Symptom Distress Score was 30.34 (13), and MDAS total was 2.01(4.03) (Table 1). There was no significant difference in the frequency of the follow-up visits between COVID + ve patients, 4 $(2,9)$, and COVID-ve patients, $4(2,8), p=0.96$. The COVID-19 + PC patients were more frequently seen virtually $(P<0.001)$, had lower depression $(P=0.035)$, and spiritual distress scores $(P=0.003)$ (Table 1). Table 2 shows that there was no significant difference in patient demographics and clinical characteristics among converters, and COVID-19-ve PC patients. Converters were referred earlier to PC consult than COVID + PC patients diagnosed prior (mean (SD), in days 1.65 (1.5) vs. 4.6 (7.25), $P=0.011$ ). Converters had higher symptom distress score (39 (9.15) vs. $26(11.7), P=0.007)$, lower MDAS scores $(0.60(0.8)$ vs. $1.65(2.3), P=0.014)$, compared to COVID + PC patients diagnosed prior to PC consult (Table 2). A total of 51/66 (77\%) of COVID-19+ve PC patients and 634/1314 (48\%) of COVID-19+ve PC patients $(P<0.001)$ were seen virtually. Overall, patients seen virtually compared in-person by $\mathrm{PC}$ were younger $(p=0.02)$, majority were white $(P=0.067)$, and had lower delirium $(P=0.007)$ (Table 3$)$.

\section{Discussion}

Our study reports the frequency and characteristics of COVID-19 + ve status among advanced cancer patients referred to inpatient PC at a tertiary cancer center during the COVID-19 pandemic. Findings of our study suggest that during pandemic, most of the inpatient PC patients did not have COVID-19 infections or related complications. The symptom burden (as assessed using ESAS SDS scores) was not significantly different between COVID + ve and COVID-ve patients, but ESAS depression and spiritual distress scores were significantly higher (worse) in COVID-ve patients. The possible reasons for higher scores in COVID-ve patients may be the stress related to fear of contracting COVID-19 infection, and 
Table 2 Patient demographics and characteristics of inpatient supportive care patients who were COVID-switchers and COVID-non-switchers

\begin{tabular}{|c|c|c|c|c|}
\hline Covariates & Total & Non-switchers & Switchers & $\begin{array}{l}\text { Fisher's exact } \\
\text { p-value* }\end{array}$ \\
\hline \multicolumn{5}{|l|}{ Gender, $(N \%)$} \\
\hline Female & $74(59.2 \%)$ & $64(57.7 \%)$ & $10(71.4 \%)$ & 0.39 \\
\hline \multicolumn{5}{|l|}{ Race, $(N \%)$} \\
\hline White & $84(67.2 \%)$ & $78(70.3 \%)$ & $6(42.9 \%)$ & \multirow[t]{4}{*}{.064} \\
\hline African American & $23(18.4 \%)$ & $17(15.3 \%)$ & $6(42.9 \%)$ & \\
\hline Asian & $8(6.4 \%)$ & $7(6.3 \%)$ & $1(7.1 \%)$ & \\
\hline Other & $10(8 \%)$ & $9(8.1 \%)$ & $1(7.1 \%)$ & \\
\hline \multicolumn{5}{|l|}{ Ethnicity } \\
\hline Hispanic or Latino & $22(17.6 \%)$ & $19(17.1 \%)$ & $3(21.4 \%)$ & \multirow[t]{3}{*}{0.37} \\
\hline Not Hispanic or Latino & $99(79.2 \%)$ & $89(80.2 \%)$ & $10(71.4 \%)$ & \\
\hline Unknown & $4(3.2 \%)$ & $3(2.7 \%)$ & $1(7.1 \%)$ & \\
\hline \multicolumn{5}{|l|}{ Cancer diagnosis } \\
\hline Breast & $7(5.6 \%)$ & $4(3.6 \%)$ & $3(21.4 \%)$ & \multirow[t]{8}{*}{0.082} \\
\hline Gastrointestinal & $29(23.2 \%)$ & $26(23.4 \%)$ & $3(21.4 \%)$ & \\
\hline Genitourinary & $16(12.8 \%)$ & $16(14.4 \%)$ & $0(0.0 \%)$ & \\
\hline Gynecological & $19(15.2 \%)$ & $16(14.4 \%)$ & $3(21.4 \%)$ & \\
\hline Head and neck & $5(4.0 \%)$ & $5(4.5 \%)$ & $0(0.0 \%)$ & \\
\hline Hematologic & $23(18.4 \%)$ & $18(16.2 \%)$ & $5(35.7 \%)$ & \\
\hline Other & $7(5.6 \%)$ & $7(6.3 \%)$ & $0(0.0 \%)$ & \\
\hline Thoracic & $19(15.2 \%)$ & $19(17.1 \%)$ & $0(0.0 \%)$ & \\
\hline \multicolumn{5}{|l|}{ Insurance } \\
\hline Government insurance & $47(37.6 \%)$ & $42(36.9 \%)$ & $5(35.7 \%)$ & \multirow[t]{3}{*}{1.00} \\
\hline Private insurance & $67(53.6 \%)$ & $59(53.2 \%)$ & $8(57.1 \%)$ & \\
\hline Self-pay & $11(8.8 \%)$ & $10(9.0 \%)$ & $1(7.1 \%)$ & \\
\hline \multicolumn{5}{|l|}{ Visit type } \\
\hline In person & $62(49.6 \%)$ & $58(52.3 \%)$ & $4(28.6 \%)$ & \multirow[t]{2}{*}{0.095} \\
\hline Telemedicine & $63(50.4 \%)$ & $53(47.7 \%)$ & $10(71.4 \%)$ & \\
\hline \multicolumn{5}{|l|}{ CAGE } \\
\hline $0-1$ & $109(94 \%)$ & $99(95.2 \%)$ & $10(83.3 \%)$ & \multirow[t]{3}{*}{0.20} \\
\hline $2-4$ & $7(6 \%)$ & $5(4.8 \%)$ & $2(16.7 \%)$ & \\
\hline Missing & 9 & 7 & 2 & \\
\hline \multicolumn{5}{|l|}{ ECOG } \\
\hline $0-2$ & $73(58.8 \%)$ & $63(57.3 \%)$ & $10(71.5 \%)$ & \multirow[t]{2}{*}{0.15} \\
\hline \multirow[t]{2}{*}{$3-4$} & $51(41.1 \%)$ & $47(42.8 \%)$ & $4(28.5 \%)$ & \\
\hline & $N$, mean $(S D)$ & $N$, mean $(S D)$ & $N$, mean $(S D)$ & $p$-value $* *$ \\
\hline Age & $125,58.48(12.62)$ & $111,58.92(12.81)$ & $14,55(10.74)$ & 0.27 \\
\hline \multicolumn{5}{|l|}{ ESAS } \\
\hline Anxiety & $120,3.02(3.16)$ & $107,3.11(3.19)$ & $13,2.23(2.92)$ & 0.34 \\
\hline Anorexia & $117,5.03(3.41)$ & $106,5(3.42)$ & $11,5.36(3.41)$ & 0.74 \\
\hline Depression & $117,1.82(2.71)$ & $105,1.91(2.76)$ & $12,1(2.13)$ & 0.27 \\
\hline Drowsiness & $117,2.51(2.76)$ & $105,2.58(2.81)$ & $12,1.92(2.23)$ & 0.43 \\
\hline Fatigue & $121,6.07(2.47)$ & $108,6.06(2.45)$ & $13,6.23(2.68)$ & 0.81 \\
\hline Financial distress & $89,1.13(2.51)$ & $80,1.11(2.43)$ & $9,1.33(3.32)$ & 0.80 \\
\hline Nausea & $123,1.64(2.5)$ & $110,1.55(2.54)$ & $13,2.46(2.11)$ & 0.21 \\
\hline Pain & $123,5.54(3.18)$ & $110,5.38(3.16)$ & $13,6.85(3.16)$ & 0.12 \\
\hline Sleep & $115,4.15(3.44)$ & $104,4.01(3.4)$ & $11,5.45(3.67)$ & 0.19 \\
\hline Dyspnea & $120,1.82(2.62)$ & $108,1.69(2.52)$ & $12,3(3.28)$ & 0.10 \\
\hline Spiritual distress & $100,46(1.54)$ & $91, .51(1.61)$ & $9,0(0)$ & 0.35 \\
\hline Feelings of well-being & $92,4.49(2.59)$ & $84,4.44(2.53)$ & $8,5(3.3)$ & 0.56 \\
\hline Symptom distress score & $89,31.69(13.05)$ & $81,30.96(13.2)$ & $8,39(9.13)$ & 0.10 \\
\hline
\end{tabular}


Table 2 (continued)

\begin{tabular}{lllll}
\hline Covariates & Total & Non-switchers & Switchers & $\begin{array}{l}\text { Fisher's exact } \\
\text { p-value* }\end{array}$ \\
\hline MDAS & $119,2.14(4.45)$ & $107,2.32(4.66)$ & $12, .58(.79)$ & 0.20 \\
$\begin{array}{l}\text { Admission to inpatient sup- } \\
\text { portive care consultation, } \\
\text { days }\end{array}$ & $125,2.34(4.45)$ & $111,2.42(4.68)$ & $14,1.64(1.82)$ & 0.54 \\
\hline
\end{tabular}

Abbreviations: SD, standard deviation; ECOG Performance Status, Eastern Cooperative Oncology Group performance status; CAGE-AID, Cut Down-Annoyed-Guilty-Eye Opener assessment; ESAS, Edmonton Symptom Assessment System; SDS, ESAS Symptom Distress Score; MDAS, Memorial Delirium Assessment Scale

* $P$ value was estimated by Chi2/Fisher's exact test

${ }^{* *} P$ value was estimated by $t$ test

isolation from their loved ones. Further studies are needed to evaluate the beneficial effects of cognitive behavioral therapy, and acceptance and commitment therapy, and educational counseling interventions regard to cancer and COVID-19 which may alleviate the stress related to cancer and contracting COVID-19 infections. There was also no association between COVID + ve status and proximity to date of receiving cancer-directed treatment or CAGEAID scores in our study. However, the association of CAGE-AID + status and prognosis and increased alcohol use during pandemic were not investigated in this study. Further studies are needed. Additionally, patients who were COVID-19 converters after PC consult had higher symptom distress scores and lower delirium score than PC patients diagnosed with COVID-19 prior to PC consults. Qian et al. found similar findings suggesting that COVID-19-ve cancer patients have high levels of anxiety and depressed mood related to patients expressed fear of becoming infected themselves (85\%) or their family (91\%), and of cancer progression due to treatment delay (91\%) [21]. Prior studies also found higher level of distress and burnout among health care providers taking care hospitalized non-COVID-19 cancer patients than COVID-19 patients [7, 22]. Therefore, there is great need to provide psychosocial support addressing the COVID-19-related fears among PC patients and teams. Review of literature suggests that prior studies in COVID + ve patients seen by PC were either all disease types or were previously healthy adults and were currently diagnosed with symptomatic COVID-19 infection. They found higher distress among symptomatic COVID-19 + ve patients. Among various symptoms, they found a higher frequency of dyspnea and delirium among severely ill COVID-19 + patients referred to PC and these symptoms improved with optimal PC [8, 23].

There was no difference in demographics, patient clinical characteristics between converters, and PC patients without COVID-19. The findings of study also suggest that $21 \%$ of patients were COVID-19+after the initial PC consultation.
These results suggest that during a new pandemic, universal virtual care might be emphasized especially at initial encounters after admission to prevent the spread of the contagion via the PC providers. In cases where virtual care is not possible, there is a critical need to follow COVID-19 PPE precautions in all PC patients as it may not be possible to distinguish COVID-19 + compared to COVID-ve, and some PC patients may be diagnosed with COVID19 infection after PC consult. Our team has taken several COVID-19 precautions as per the CDC, state, and institutional guidelines for preventing spread of COVID-19 infection, as well as measures such as providing virtual care, and daily morning patients update list ("COVID-19 Tracking and Alert List") to the PC clinicians informing them regard to COVID-19 + ve PC patients, especially those who switched positive after completion of the PC consultation (converters). Since completion of our project, PC providers were provided access to PPE in all the hospital floors due to availability of supply, and virtual care is provided to all patients whenever possible. Further studies are needed.

We found that patients seen virtually compared to those seen in-person by PC were younger and had lower delirium scores. The variation in usability of virtual care among older PC patients may be due to the fact that younger patients are more familiar with technology to operate their mobile phones or tablets so as to conduct a virtual visit as compared to older PC patients [24, 25], and on the other hand, delirious patients are unable to communicate virtually due to cognition. Family members can play a major role in facilitating the $\mathrm{PC}$ virtual visits especially in older cancer patients with visual, auditory, cognitive impairment, or having significant symptom distress or limited digital literacy while admitted in the hospital [26-28]. The caregiver can be "trained" to do the virtual visit and can potentially interpret the visit for the patient and communicate the patients' responses to the supportive care clinician. However, the role of family may have been limited in the PC virtual visits in our study due to a strict visitor policy to limit COVID-19 infections (Appendix A). 
Table 3 Patient demographics and characteristics of inpatient supportive care patients seen in person visit vs. telemedicine (virtual) visit

\begin{tabular}{|c|c|c|c|c|c|c|}
\hline \multirow{2}{*}{$\begin{array}{l}\text { Outcomes } \\
\text { Gender }(N \%)\end{array}$} & & \multicolumn{2}{|l|}{ Total } & \multirow[t]{2}{*}{ In person } & \multicolumn{2}{|l|}{ Telemedicine } \\
\hline & & & & & & $p$-value* \\
\hline Female & & $111(55.5 \%)$ & & $51(50 \%)$ & $60(60 \%)$ & 0.20 \\
\hline \multicolumn{7}{|l|}{ Race $(N \%)$} \\
\hline White & & $136(68 \%)$ & & $66(66 \%)$ & $70(70 \%)$ & 0.067 \\
\hline African American & & $34(17 \%)$ & & $19(19 \%)$ & $15(15 \%)$ & \\
\hline Asian & & $13(6.5 \%)$ & & $10(10 \%)$ & $3(3 \%)$ & \\
\hline Other & & $17(8.5 \%)$ & & $5(5 \%)$ & $12(12 \%)$ & \\
\hline \multicolumn{7}{|l|}{ Ethnicity } \\
\hline Hispanic or Latino & & $39 \mathrm{v}(19.5 \%)$ & & $20(20 \%)$ & $19(19 \%)$ & 0.28 \\
\hline Not Hispanic or Latino & & $155 \mathrm{v}(77.5 \%)$ & & $75(75 \%)$ & $80(80 \%)$ & \\
\hline \multicolumn{7}{|l|}{ CAGE $(N \%)$} \\
\hline $0-1$ & & $166(94.3 \%)$ & & $83(95.4 \%)$ & $83(93.3 \%)$ & 1.00 \\
\hline $2-4$ & & $10 \mathrm{v}(5.6 \%)$ & & $4(4.6 \%)$ & $6(6.8 \%)$ & \\
\hline \multicolumn{7}{|l|}{$\operatorname{ECOG}(N \%)$} \\
\hline $0-2$ & & $113(57.4 \%)$ & & $51(52.6 \%)$ & $62(62 \%)$ & 0.40 \\
\hline $3-4$ & & $84(42.6)$ & & $46(47.4 \%)$ & $38(38 \%)$ & \\
\hline \multicolumn{7}{|l|}{ Cancer diagnosis } \\
\hline Breast & & $12(6 \%)$ & & $6(6 \%)$ & $6(6 \%)$ & 0.24 \\
\hline Gastrointestinal & & $43(21.5 \%)$ & & $20(20 \%)$ & $23(23 \%)$ & \\
\hline Genitourinary & & $23(11.5 \%)$ & & $10(10 \%)$ & $13(13 \%)$ & \\
\hline Gynecological & & $26(13 \%)$ & & $8(8 \%)$ & $18(18 \%)$ & \\
\hline Head and neck & & $11(5.5 \%)$ & & $8(8 \%)$ & $3(3 \%)$ & \\
\hline Hematologic & & $42(21 \%)$ & & $20(20 \%)$ & $22(22 \%)$ & \\
\hline Thoracic & & $26(13 \%)$ & & $18(18 \%)$ & $8(8 \%)$ & \\
\hline Other & & $17(8.5 \%)$ & & $4(4 \%)$ & $3(3 \%)$ & \\
\hline \multicolumn{7}{|l|}{ Insurance } \\
\hline Government & & $83(20.5 \%)$ & & $45(45 \%)$ & $38(38 \%)$ & 0.32 \\
\hline Private insurance & & $99(49.5 \%)$ & & $48(48 \%)$ & $51(51 \%)$ & \\
\hline Self-pay & & $18(9 \%)$ & & $7(7 \%)$ & $11(11 \%)$ & \\
\hline Variables & $N$, mean (SD) & & $N$, mean (SD) & & $N$, mean (SD) & $p$-value ** \\
\hline Age & $200,58.6(13.9)$ & & $100,60.9(13.5)$ & & $100,56.4(14)$ & 0.022 \\
\hline \multicolumn{7}{|l|}{ ESAS } \\
\hline Anxiety & $173,3.05(3.3)$ & & $87,3.13(3.34)$ & & $86,2.97(3.22)$ & 0.75 \\
\hline Anorexia & $163,5.15(3.32)$ & & $82,5.44(3.32)$ & & $81,4.85(3.32)$ & 0.26 \\
\hline Depression & $171,1.82(2.77)$ & & $86,1.76(2.82)$ & & $85,1.88(2.74)$ & 0.77 \\
\hline Drowsiness & $171,2.48(2.83)$ & & $85,2.47(2.96)$ & & $86,2.49(2.7)$ & 0.97 \\
\hline Fatigue & $176,5.88(2.57)$ & & $88,6.07(2.52)$ & & $88,5.68(2.62)$ & 0.32 \\
\hline Financial distress & $125,1.25(2.68)$ & & $65,1.05(2.46)$ & & $60,1.47(2.9)$ & 0.38 \\
\hline Nausea & $179,1.8(2.76)$ & & $89,1.91(2.94)$ & & $90,1.69(2.6)$ & 0.59 \\
\hline Pain & $181,5.43(3.15)$ & & $89,5.84(2.96)$ & & $92,5.02(3.3)$ & 0.079 \\
\hline Sleep disturbance & $165,4.1(3.42)$ & & $81,4.48(3.37)$ & & $84,3.73(3.44)$ & 0.16 \\
\hline Dyspnea & $177,1.94(2.73)$ & & $88,2.08(2.82)$ & & $89,1.8(2.64)$ & 0.49 \\
\hline Spiritual distress & $140,4(1.43)$ & & $69, .45(1.6)$ & & $71, .35(1.23)$ & 0.69 \\
\hline Well-being & $127,4.43(2.6)$ & & $69,4.75(2.54)$ & & $58,4.03(2.64)$ & 0.12 \\
\hline Symptom distress scale & $118,31.62(13.5)$ & & $63,32.46(13.17)$ & & $55,30.65(13.94)$ & 0.47 \\
\hline MDAS & $192,2.33(4.22)$ & & $96,3.16(5.3)$ & & $96,1.51(2.56)$ & 0.007 \\
\hline $\begin{array}{l}\text { Admission to inpatient supportive } \\
\text { care consultation, days }\end{array}$ & $200,2.83(5.4)$ & & $100,2.35(3.43)$ & & $100,3.31(6.8)$ & 0.21 \\
\hline
\end{tabular}

Bolded $P$ values indicate a statistically significant difference

Abbreviations: SD, standard deviation; ECOG Performance Status, Eastern Cooperative Oncology Group performance status; CAGE-AID, Cut Down-Annoyed-Guilty-Eye Opener assessment; ESAS, Edmonton Symptom Assessment System; SDS, ESAS Symptom Distress Score; MDAS, Memorial Delirium Assessment Scale

* $P$ value was estimated by $\mathrm{Chi}^{2} /$ Fisher's exact test

${ }^{* *} P$ value was estimated by $t$ test 
Further studies are needed to assess the benefit of patient health aids or navigators to support patients with virtual PC visits. In addition, further studies are needed to characterize the patients who are unable to receive virtual care and may need in person (face-face) care.

The study has several limitations. These includes the retrospective nature of the study, a single tertiary cancer setting, small sample size of COVID + ve PC patients, and no correction were made for multiple comparisons. Therefore, interpretation of results must be made more cautiously. In our study, we have also not assessed the impact of COVID19 on family distress in PC patients' family caregivers using a validated questionnaire. Further studies are needed.

\section{Conclusion}

The burden of COVID-19+ status among patients referred PC was low. COVID-19+ ve patients had more frequent virtual visits, lower depression, and spiritual distress scores. Patients seen virtually were significantly younger and had lower delirium. The virtual encounter reduced the risk of contagion for the PC clinicians, and it allowed continuity of care. During a new pandemic, universal virtual care might be emphasized especially at initial encounters after admission. Further research is needed on the potential efficacy of this intervention.

Supplementary Information The online version contains supplementary material available at https://doi.org/10.1007/s00520-021-06525-x.

\begin{abstract}
Author contribution Dr Sriram Yennurajalingam had full access to all data in the study and takes responsibility for the integrity of the data and the accuracy of the data analysis. Concept and design: Yennurajalingam, Bruera. Acquisition, analysis, or interpretation of data: Yennurajalingam, Minxing Chen, Zhanni Lu, and Bruera. Drafting of the manuscript: Yennurajalingam, Minxing Chen, Zhanni Lu, and Bruera. Critical revision of the manuscript for important intellectual content: Yennurajalingam, Minxing Chen, Zhanni Lu, and Bruera. Statistical analysis: Minxing Chen. Administrative, technical, or material support: Yennurajalingam, Bruera. Supervision: Yennurajalingam, Bruera.
\end{abstract}

Data availability The data presented in this study are available on request from the corresponding author.

Code availability Available on request from the corresponding author.

\section{Declarations}

Ethics approval The University of Texas MD Anderson Cancer Center Institutional Review Board approved the protocol.

Consent to participate Institutional Review Board waived the informed consent for this retrospective study.
Consent for publication Institutional Review Board waived the informed consent for this retrospective study.

Conflict of interest The authors declare no conflict of interest related to study. Sriram Yennurajalingam, Helsinn (research funding for fatigue study), Bayer (research funding for fatigue study), Genentech (research funding for palliative care study); and Eduardo Bruera (Helsinn: research funding for palliative care study). All other authors declare no conflict of interest.

\section{References}

1. Wang R, Zhang X, Irwin DM, Shen Y (2020) Emergence of SARS-like coronavirus poses new challenge in China. J Infect 80(3):350-371. https://doi.org/10.1016/j.jinf.2020.01.017

2. Tang JW, Tambyah PA, Hui DSC (2020) Emergence of a novel coronavirus causing respiratory illness from Wuhan, China. J Infect 80(3):350-371. https://doi.org/10.1016/j.jinf.2020.01.014

3. Temel JS, Greer JA, Muzikansky A, Gallagher ER, Admane S, Jackson VA, Dahlin CM, Blinderman CD, Jacobsen J, Pirl WF, Billings JA, Lynch TJ (2010) Early palliative care for patients with metastatic non-small-cell lung cancer. N Engl J Med 363(8):733-742. https://doi.org/10.1056/NEJMoa1000678

4. Zimmermann C, Riechelmann R, Krzyzanowska M, Rodin G, Tannock I (2008) Effectiveness of specialized palliative care: a systematic review. JAMA 299(14):1698-1709. https://doi.org/ 10.1001/jama.299.14.1698

5. Dalal S, Palla S, Hui D, Nguyen L, Chacko R, Li Z, Fadul N, Scott C, Thornton V, Coldman B, Amin Y, Bruera E (2011) Association between a name change from palliative to supportive care and the timing of patient referrals at a comprehensive cancer center. Oncologist 16(1):105-111. https://doi.org/10. 1634/theoncologist.2010-0161

6. Fadul N, Elsayem A, Palmer JL, Del Fabbro E, Swint K, Li Z, Poulter V, Bruera E (2009) Supportive versus palliative care: what's in a name?: a survey of medical oncologists and midlevel providers at a comprehensive cancer center. Cancer 115(9):2013-2021. https://doi.org/10.1002/cncr.24206

7. Varani S, Ostan R, Franchini L, Ercolani G, Pannuti R, Biasco G, Bruera E (2021) Caring advanced cancer patients at home during COVID-19 outbreak: burnout and psychological morbidity among palliative care professionals in Italy. J Pain Symptom Manage 61(2):e4-e12. https://doi.org/10.1016/j.jpainsymman. 2020.11.026

8. Lopez S, Finuf KD, Marziliano A, Sinvani L, Burns EA (2021) Palliative care consultation in hospitalized patients with COVID-19: a retrospective study of characteristics, outcomes, and unmet needs. J Pain Symptom Manage. https://doi.org/10. 1016/j.jpainsymman.2020.12.015

9. Oken MM, Creech RH, Tormey DC, Horton J, Davis TE, McFadden ET, Carbone PP (1982) Toxicity and response criteria of the Eastern Cooperative Oncology Group. Am J Clin Oncol 5(6):649-655

10. Bruera E, Kuehn N, Miller MJ, Selmser P, Macmillan K (1991) The Edmonton Symptom Assessment System (ESAS): a simple method for the assessment of palliative care patients. J Palliat Care 7(2):6-9

11. Cheung WY, Barmala N, Zarinehbaf S, Rodin G, Le LW, Zimmermann C (2009) The association of physical and psychological symptom burden with time to death among palliative cancer 
outpatients. J Pain Symptom Manage 37(3):297-304. https:// doi.org/10.1016/j.jpainsymman.2008.03.008

12. Ewing JA (1984) Detecting alcoholism: the CAGE Questionnaire. JAMA 252(14):1905-1907. https://doi.org/10.1001/jama. 1984.03350140051025

13. Parsons HA, Delgado-Guay MO, El Osta B, Chacko R, Poulter V, Palmer JL, Bruera E (2008) Alcoholism screening in patients with advanced cancer: impact on symptom burden and opioid use. J Palliat Med 11(7):964-968. https://doi.org/10.1089/jpm. 2008.0037

14. Yennurajalingam S, Arthur J, Reddy S, Edwards T, Lu Z, Rozman de Moraes A, Wilson SM, Erdogan E, Joy MP, Ethridge SD, Kuriakose L, Malik JS, Najera JM, Rashid S, Qian Y, Kubiak MJ, Nguyen K, PharmD WuJ, Hui D, Bruera E (2021) Frequency of and factors associated with nonmedical opioid use behavior among patients with cancer receiving opioids for cancer pain. JAMA Oncol 7(3):404-411. https://doi.org/10.1001/jamaoncol. 2020.6789

15. Breitbart W, Rosenfeld B, Roth A, Smith MJ, Cohen K, Passik S (1997) The memorial delirium assessment scale. J Pain Symptom Manage 13(3):128-137. https://doi.org/10.1016/S0885-3924(96) 00316-8

16. Lawlor PG, Fainsinger RL, Bruera ED (2000) Delirium at the end of lifecritical issues in clinical practice and research. JAMA 284(19):2427-2429. https://doi.org/10.1001/jama.284.19.2427

17. de la Cruz M, Reddy A, Vidal M, Tanco K, Azhar A, Silvestre J, Liu DD, Wu J, Bruera E (2016) Impact of a palliative care checklist on clinical documentation. J Oncol Pract 12(2):e241-e247. https://doi.org/10.1200/JOP.2015.007203

18. de la Cruz M, Fan J, Yennu S, Tanco K, Shin S, Wu J, Liu D, Bruera E (2015) The frequency of missed delirium in patients referred to palliative care in a comprehensive cancer center. Support Care Cancer 23(8):2427-2433. https://doi.org/10.1007/ s00520-015-2610-3

19. Reddy A, Vidal M, de la Cruz M, Yennurajalingam S, Bruera E (2014) Snapshot of an acute palliative care unit in a tertiary cancer hospital. Palliat Support Care 12(4):331-337. https://doi.org/10. 1017/s1478951513000722

20. European Society of Medical Oncology. ESMO clinical practice guidelines: supportive and palliative care https://www.esmo.org/ guidelines/supportive-and-palliative-care (Last accessed August 2021)
21. Qian Y, Wu K, Xu H, Bao D, Ran F, Wei W, Cheng T, Huang D, Lin X, Bruera E, Hu D, Wu Y (2020) A survey on physical and mental distress among cancer patients during the COVID-19 epidemic in Wuhan, China. J Palliat Med 23(7):888-889. https:// doi.org/10.1089/jpm.2020.0240

22. Wu Y, Wang J, Luo C, Hu S, Lin X, Anderson AE, Bruera E, Yang X, Wei S, Qian Y (2020) A comparison of burnout frequency among oncology physicians and nurses working on the frontline and usual wards during the COVID-19 epidemic in Wuhan. China J Pain Symptom Manage 60(1):e60-e65. https://doi.org/10.1016/j. jpainsymman.2020.04.008

23. Hetherington L, Johnston B, Kotronoulas G, Finlay F, Keeley P, McKeown A (2020) COVID-19 and Hospital Palliative Care - a service evaluation exploring the symptoms and outcomes of 186 patients and the impact of the pandemic on specialist Hospital Palliative Care. Palliat Med 34(9):1256-1262. https://doi.org/10. 1177/0269216320949786

24. Lam K, Lu AD, Shi Y, Covinsky KE (2020) Assessing telemedicine unreadiness among older adults in the United States during the COVID-19 pandemic. JAMA Intern Med 180(10):1389-1391. https://doi.org/10.1001/jamainternmed.2020.2671

25. Cimperman M, Brenčič MM, Trkman P, Stanonik Mde L (2013) Older adults' perceptions of home telehealth services. Telemed J E Health 19(10):786-790. https://doi.org/10.1089/tmj.2012.0272

26. Webb M, Hurley SL, Gentry J, Brown M, Ayoub C (2021) Best practices for using telehealth in hospice and palliative care. Journal of hospice and palliative nursing : JHPN : the official journal of the Hospice and Palliative Nurses Association 23(3):277-285. https://doi.org/10.1097/njh.0000000000000753

27. Allen Watts K, Malone E, Dionne-Odom JN, McCammon S, Currie E, Hicks J, Tucker RO, Wallace E, Elk R, Bakitas M (2021) Can you hear me now?: improving palliative care access through telehealth. Res Nurs Health 44(1):226-237. https://doi.org/10. 1002/nur.22105

28. Weaver MS, Neumann ML, Navaneethan H, Robinson JE, Hinds PS (2020) Human touch via touchscreen: rural nurses' experiential perspectives on telehealth use in pediatric hospice care. J Pain Symptom Manage 60(5):1027-1033. https://doi.org/10.1016/j. jpainsymman.2020.06.003

Publisher's note Springer Nature remains neutral with regard to jurisdictional claims in published maps and institutional affiliations. 